Check for updates

Cite this: Mater. Chem. Front. 2019, 3, 1422

Received 26th February 2019, Accepted 30th April 2019

DOI: $10.1039 / c 9 q m 00128$

rsc.li/frontiers-materials

\section{Divergent synthesis of 3-substituted thieno[3,4-b]thiophene derivatives via hydroxy-based transformations $\dagger$}

\begin{abstract}
Yue Zhou, Jie Hao and Dongbing Zhao (D) *
Herein, we have developed the first $\mathrm{Pd}$-catalytic method for the preparation of 3-hydroxythieno[3,4b]thiophene-2-carboxylate, which can be widely utilized as the chemical building block for modular assembly of structurally diverse 3-substituted thieno[3,4-b]thiophene derivatives via hydroxy-based transformation. Furthermore, we have evaluated the effect on their photophysical properties of the introduction of different substitutions at the C3-position and prepared conjugated polymers bearing 3 -substituted thieno[3,4-b]thiophene units. We demonstrated that the photoluminescence $(\mathrm{PL})$ properties of thieno[3,4-b]thiophene-2-carboxylate can be efficiently modulated by introducing different functional groups at the C3-position.
\end{abstract}

As is well recognized, thiophene-based conjugated molecules have played an indispensable role in the development of organic optoelectronics. ${ }^{1}$ Among various thiophene building blocks, the thieno-[3,4- $b]$ thiophene (TT) unit with functional groups has recently emerged as an extremely attractive electron-withdrawing building block in organic electronics. ${ }^{2}$ In particular, thieno[3,4$b]$ thiophenes (TbTs) bearing a carboxyl group have been widely used in the development of donor and acceptor materials in organic solar cells (OSCs) represented by the PTB series family polymers and IDT-derived non-fullerene small molecules acceptors with state-of-the-art power conversion efficiencies (PCEs) (Scheme 1). ${ }^{3-5}$ Thieno[3,4-b]thiophene (TbT) is an asymmetric fused bithiophene containing four functionalization positions, in which the proaromatic thiophene can effectively stabilize the quinoidal resonance of the aromatic thiophene, narrow the energy gap, and modulate the electronic structures of the resulting molecules.

Historically, synthesis of thieno[3,4-b]thiophenes (TbTs) bearing a carboxyl group involved: (1) Cu-mediated coupling between 4-bromothiophene-3-carbaldehyde and 2-mercaptoacetate (Scheme 2a). ${ }^{6}$ However, this method is suitable only for the preparation of 3-unsubsituted thieno[3,4- $b]$ thiophenes; (2) the non-catalytic multi-step cyclization reaction from 3-substituted thiophene-2-carboxylate (Scheme 2b). ${ }^{7}$ Even though this method has the capacity to access 3 -substituted thieno[3,4- $b]$ thiophenes, it still suffers from disadvantages such as linear multi-step

State Key Laboratory and Institute of Elemento-Organic Chemistry, College of Chemistry, Nankai University, 94 Weijin Road, Tianjin 300071, China. E-mail: dongbing.chem@nankai.edu.cn

$\dagger$ Electronic supplementary information (ESI) available. See DOI: 10.1039/c9qm00128j
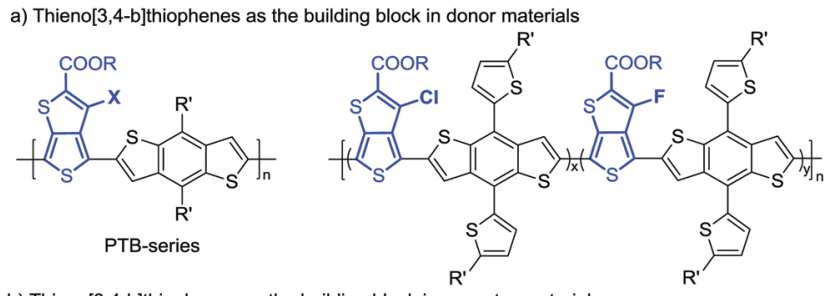

b) Thieno[3,4-b]thiophenes as the building block in acceptor materials
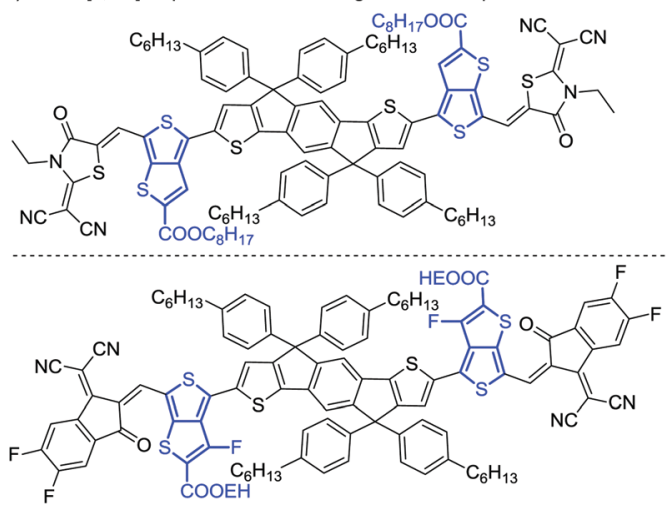

Scheme 1 Representative donor and acceptor materials bearing thieno[3,4b]thiophene-2-carboxylate units in organic solar cells.

synthesis (more than 5 steps needs for each product), low yields, harsh reaction conditions, and limited substrate scopes. Thus, development of a methodology to access thieno[3,4- $b]$ thiophenes with various substitution patterns at the 3-position in a rapid and modular manner from readily available precursors is highly appealing. Herein, we have developed the first Pd-catalytic method for the preparation of 3-hydroxythieno[3,4- $b]$ thiophene-2-carboxylate 


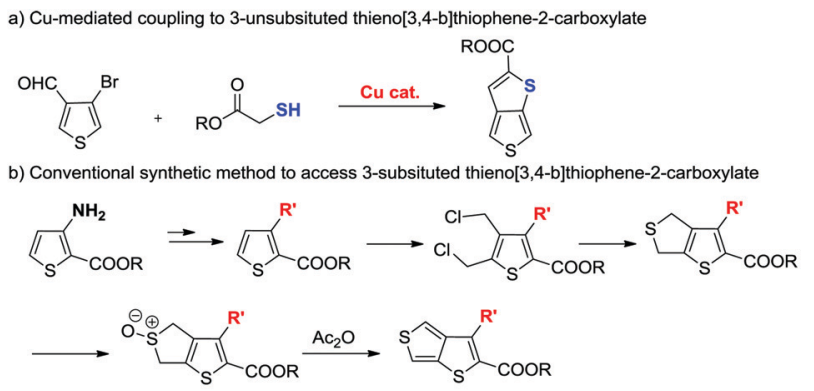

c) Accessing 3-subsituted thieno[3,4-b]thiophene-2-carboxylate via a Pd catalyzed method (This work)

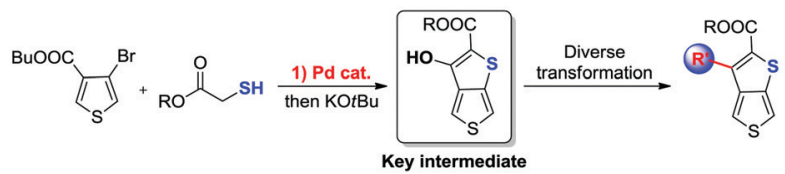

Scheme 2 The conventional synthetic methods to access thieno[3,4b] thiophene-2-carboxylates and our study.

from commercially available 4-bromothiophene-3-carboxylate and 2-mercaptoacetate (Scheme 2c), which has never been prepared before our study. We demonstrated that this 3-hydroxythieno$[3,4-b]$ thiophene-2-carboxylate can be widely utilized as a chemical building block for modular assembly of structurally diverse 3 -substituted thieno[3,4- $b]$ thiophene derivatives via a wide range of hydroxy-based transformations. Moreover, we have evaluated the effect on their photophysical properties of the introduction of different substitutions at the C3-position and then developed a series of TT-based conjugated polymer donors.

In our preliminary study, the reaction of butyl 4-bromothiophene-3-carboxylate 1a with ethyl 2-mercaptoacetate $\mathbf{2 a}$ was examined under Cu-catalytic conditions. Unfortunately, the developed Cu-catalytic system for the preparation of 3-unsubstituted thiophene-2-carboxylate was not effective for this conversion (Table 1, entries 1-3). After an extensive screening such as different $\mathrm{Pd}^{0}$ sources, solvents, reaction times and ligands, we found that treatment of $1 \mathbf{a}(0.2 \mathrm{mmol})$ and $2 \mathrm{a}$ with $\mathrm{Pd}_{2} \mathrm{dba}_{3}$ (5 mol\%), xantphos (10 mol\%) in toluene $(1 \mathrm{~mL})$ at $120{ }^{\circ} \mathrm{C}$ for

Table 1 Optimization of directed hydroarylation of unactivated alkene 1a with ethyl 2-mercaptoacetate $2 a^{a}$

\begin{tabular}{lllllll}
\hline & & & & \\
Entry & Base & Catalyst & Ligand & Solvent & Temp. $\left({ }^{\circ} \mathrm{C}\right)$ & Yield $^{b}$ \\
\hline 1 & $\mathrm{~K}_{2} \mathrm{CO}_{3}$ & $\mathrm{CuO}$ & - & DMSO & 60 & N.R. \\
2 & $\mathrm{~K}_{2} \mathrm{CO}_{3}$ & $\mathrm{CuO}$ & - & DMSO & 140 & N.R. \\
3 & $\mathrm{~K}_{2} \mathrm{CO}_{3}$ & $\mathrm{CuO}$ & Phen & DMSO & 140 & N.R. \\
$\mathbf{4}$ & $\mathrm{DIPEA}_{3}$ & $\mathbf{P d}_{2} \mathbf{d b a}_{3}$ & Xantphos & Toluene & $\mathbf{1 2 0}$ & $\mathbf{8 1}$ \\
5 & $\mathrm{~K}_{2} \mathrm{CO}_{3}$ & $\mathrm{Pd}_{2} \mathrm{dba}_{3}$ & Xantphos & Toluene & 120 & 61 \\
6 & $\mathrm{KO}^{t} \mathrm{Bu}$ & $\mathrm{Pd}_{2} \mathrm{dba}_{3}$ & Xantphos & Toluene & 120 & 21 \\
7 & $\mathrm{NaO}^{t} \mathrm{Bu}$ & $\mathrm{Pd}_{2} \mathrm{dba}_{3}$ & Xantphos & Toluene & 120 & 24 \\
8 & $\mathrm{DIPEA}_{3}$ & - & Xantphos & Toluene & 120 & N.R.
\end{tabular}

${ }^{a}$ Reactions were carried out with $[\mathrm{M}]$ catalyst (10 mol\%), ligand (10 mol\%), base (1.5 equiv.), $1 \mathrm{a}(0.2 \mathrm{mmol})$, and ethyl 2-mercaptoacetate (2a, $0.4 \mathrm{mmol})$ in solvent $(1 \mathrm{~mL})$ for $24 \mathrm{~h}$ under a $\mathrm{N}_{2}$ atmosphere. ${ }^{b}$ Yields were determined by isolation. N.R.: no reaction.
$24 \mathrm{~h}$ gave product $3 \mathrm{a}$ in $97 \%$ yield (Table 1, entry 4). Evaluation of different bases revealed that DIPEA was the best choice (entries 3-7). There is no reactivity at all in the absence of Pd catalyst (entry 8). Finally, we demonstrated that the product 3a can be smoothly cyclized to form the key intermediate 3-hydroxythieno[3,4-b]thiophene-2-carboxylate (entry 4 ) with $81 \%$ yield in the presence of $\mathrm{KO}^{t} \mathrm{Bu}$ in THF.

As we proposed, the product 3-hydroxythieno[3,4- $b]$ thiophene-2-carboxylate $\mathbf{4 a}$ obtained by the method described herein could provide access to structurally diverse 3-substituted thiophene-2-carboxylates by means of additional hydroxy-based transformations (Scheme 3). ${ }^{8}$ First, the hydroxy group of 4 a was easily methylated to yield the 3-methoxythieno[3,4- $b]$ thiophene2-carboxylate 5 using methyl iodide as the methylation reagent. 3-Methoxythieno[3,4- $b]$ thiophene-2-carboxylate $\mathbf{5}$ could further undergo bromination in the presence of NBS in DMF to yield compound 6 with $60 \%$ yield. Furthermore, the hydroxy group of 4a could also been smoothly transformed to -OTf in the presence of $\mathrm{Tf}_{2} \mathrm{O}$ /pyridine, which is a versatile leaving group in a lot of different types of cross-coupling reactions. ${ }^{9}$ For example, the -OTf of 7 can couple with $\mathrm{NaSCH}_{3}$ under Pd-catalytic conditions to produce compound 8 in $91 \%$ yield. In addition, the amination of product 7 with diphenylmethanimine in the presence of a $\mathrm{Pd}^{0}$ catalyst and $\mathrm{K}_{3} \mathrm{PO}_{4}$ in toluene also worked smoothly to afford the corresponding 9 in $86 \%$ yield. Product 7 could also undergo Suzuki coupling to yield 3-phenylthieno[3,4-b]thiophene-2-carboxylate 10 in $97 \%$ yield. Pd-Catalyzed Sonogashira coupling of product 7 and ethynylbenzene also smoothly occurred to access 3-alkynylthieno[3,4- $b]$ thiophene-2-carboxylate $\mathbf{1 1}$ with $91 \%$ yield.

After development of the modular methodology to access diverse 3-substituted thieno[3,4- $b]$ thiophene-2-carboxylates, we aimed to introduce these building blocks into conjugated polymers.

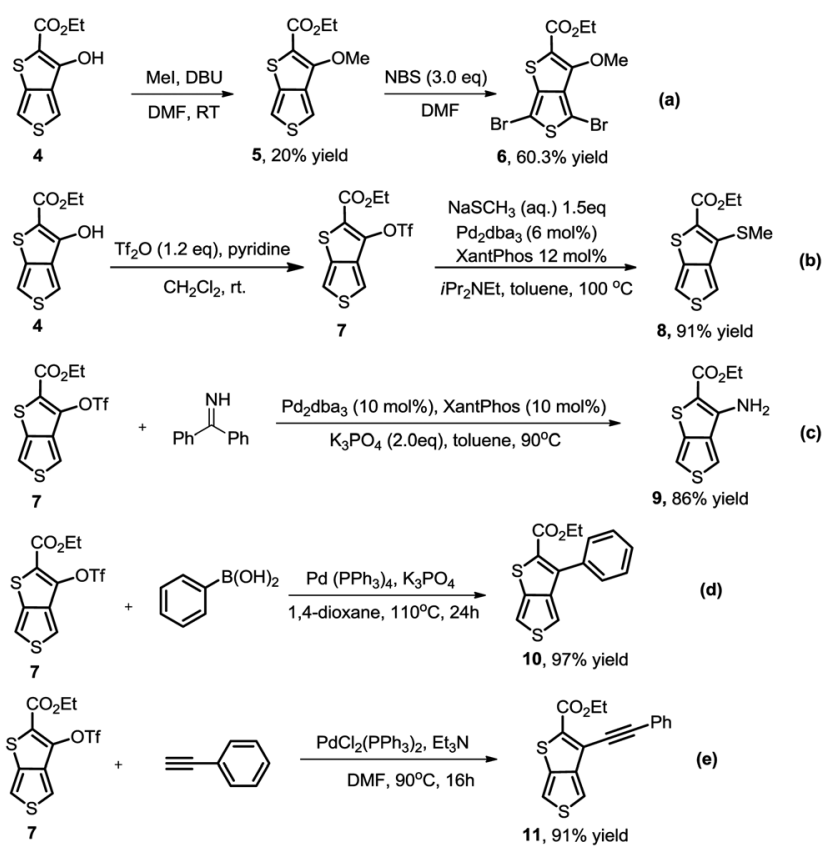

Scheme 3 Accessing structurally diverse 3-substituted thiophene-2carboxylates by means of additional hydroxy-based transformations. 

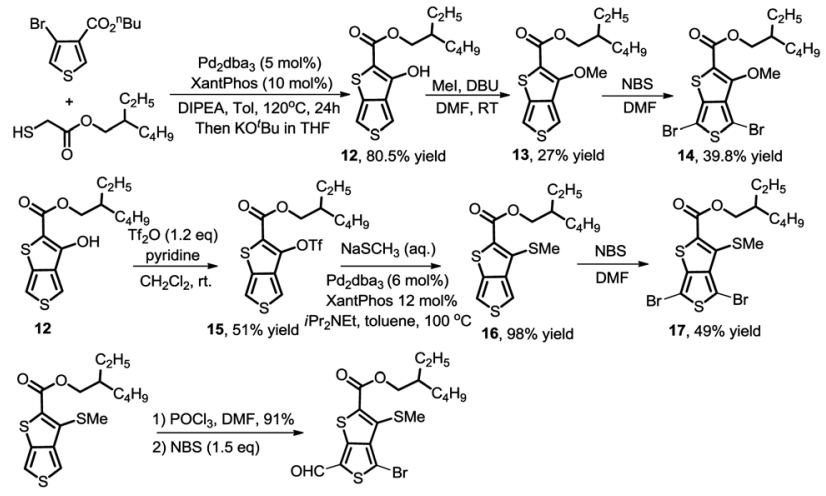

$1618,46 \%$ yield
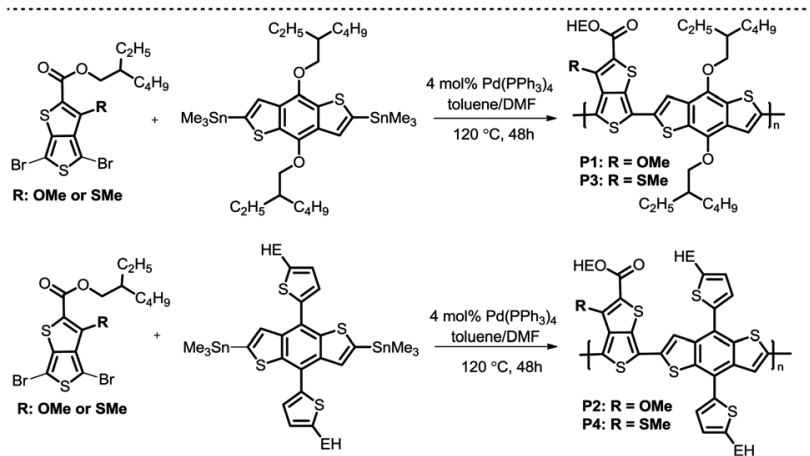

Scheme 4 The synthesis of new conjugated polymers bearing 3-methoxy or 3-methylthio TbT units.

Following the procedures developed, we synthesized the 3-methoxy and 3-methylthio TbT monomers with a branched alkyl chain to guarantee enough solubility of the polymers. The synthetic route is described in Scheme 4 (upper panel). Furthermore, we found that 4-bromo-6-formyl-3-substituted [3,4- $b]$ thiophene2-carboxylate 18 could been produced by regioselective monoformylation and sequential bromination, which can be further utilized in the development of new small molecule donors and acceptors. ${ }^{10}$ Then, a series of conjugated polymers were prepared by Stille coupling reactions of the TbT monomers and BDT-T or ${ }_{\text {BDT }}{ }^{11}$ namely P1, P2, P3, and P4 (Scheme 4, lower panel). Detailed synthetic routes and characterizations can be found in the Experimental section of the ESI. $\dagger$

We first evaluated the effect of the subsitution at the C3-position of thieno[3,4- $b]$ thiophene-2-carboxylate on their photophysical properties. The absorption maxima, photoluminescence (PL) emission maxima, and PL quantum yields $\left(\Phi_{\mathrm{f}}\right)$ of compounds TT, 5, 8, 9, 10 and 11 in both the solid state and $\mathrm{CH}_{2} \mathrm{Cl}_{2}$ solution are listed in Table 2, whereas the corresponding absorption, and emission spectra are depicted in Fig. 1 and Fig. S1 (ESI $\dagger$ ). It is worth noting that all these compounds were stable to light, humidity and air. As shown in Fig. 1, the subsitution at the C3-position was observed to greatly influence the molecular absorption and fluorescence. By incorporation of functional groups into the C3-position, all of the absorption and emission peaks of these derivatives were obviously red-shifted and their PL efficiencies were also enhanced in comparison with the ethyl $[3,4-b]$ thiophene-2-carboxylate (TT) in both the solid state
Table 2 Optical properties of 5, 8, 9, 10, 11 and $\mathrm{TT}$ in both the solid state and $\mathrm{CH}_{2} \mathrm{Cl}_{2}$ solution

\begin{tabular}{|c|c|c|c|c|c|}
\hline \multirow[b]{2}{*}{ Comp. } & \multicolumn{2}{|c|}{ UV-Vis absorption } & \multicolumn{3}{|c|}{$\underline{\text { Emission }}$} \\
\hline & $\lambda_{\max }^{\mathrm{sol}}$ & $\lambda_{\max }^{\text {film }}$ & $\lambda_{\max }^{\mathrm{sol}}$ & $\lambda_{\max }^{\text {solid }}$ & $\Phi_{\mathrm{sol}}{ }^{a}(\%)$ \\
\hline TT & 338 & 352 & 357 & n.d. & n.d. \\
\hline 5 & 352 & 388 & 409 & 499 & 3.42 \\
\hline 8 & 368 & 400 & 426 & 447 & 0.71 \\
\hline 9 & 369 & 400 & 442 & 462 & 88 \\
\hline 10 & 352 & 359 & 429 & 440 & 9.64 \\
\hline 11 & 378 & 397 & 430 & 478 & 6.5 \\
\hline
\end{tabular}

${ }^{a}$ Absolute quantum yield determined with an integrating sphere system. n.d. = not detected due to the weak emission intensity.
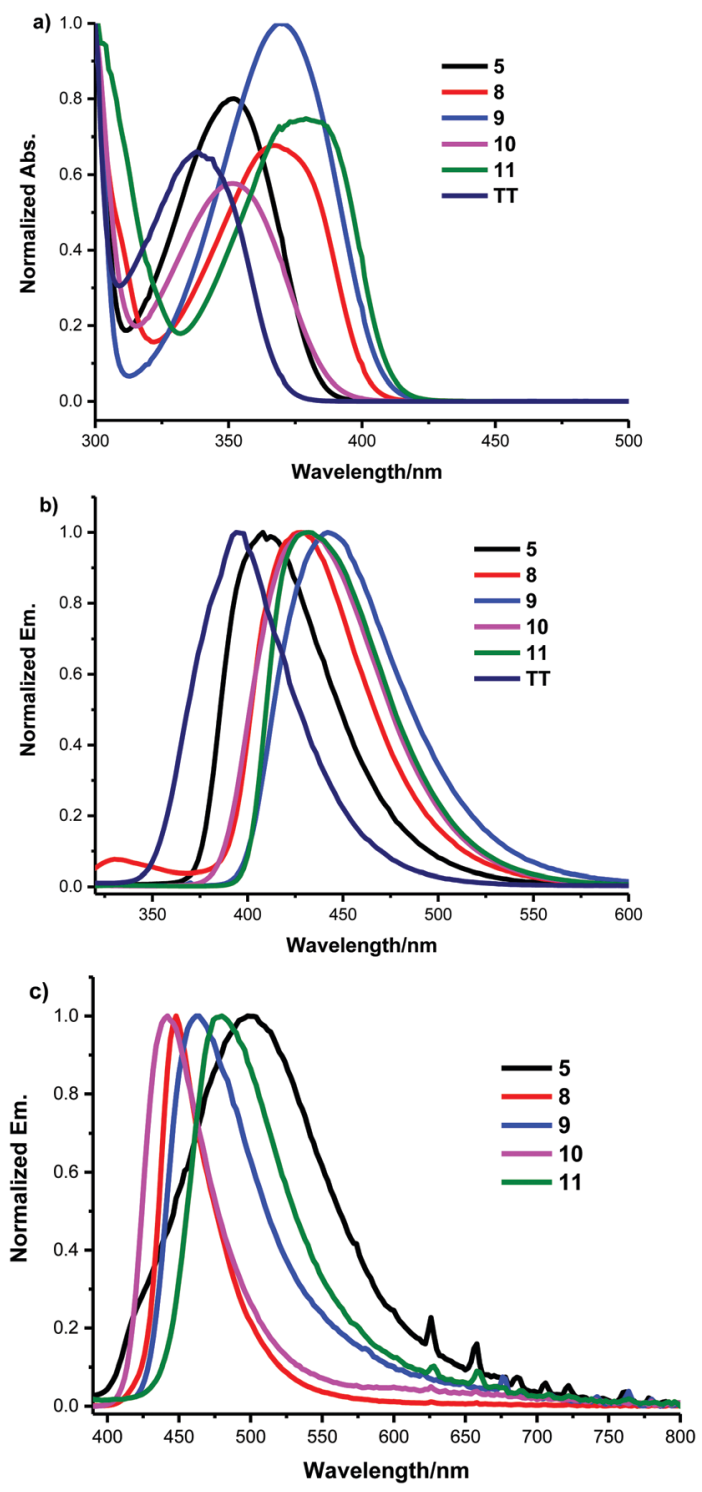

Fig. 1 (a) Normalized UV/Vis absorption spectra of 5, 8, 9, 10, 11 and ethyl[3,4-b]thiophene-2-carboxylate (TT) in a DCM solution; (b) normalized emission spectra in DCM; (c) normalized emission spectra in the solid state.

and $\mathrm{CH}_{2} \mathrm{Cl}_{2}$ solution. This might stem from the restriction of intramolecular rotation (RIR) of the ester group at the C2-position and substitution at the C3-position. Fig. $1 \mathrm{~b}$ and $\mathrm{c}$ reveal that the 
emission peaks of these monomers in thin films are different from their emissions in $\mathrm{CH}_{2} \mathrm{Cl}_{2}$. This likely indicates that these monomers involved different intermolecular interactions and molecular aggregation in the solid state and in the dilute solution state.

The optical properties of these conjugated polymers bearing 3-methoxy and 3-methylthio TbT units in solution and in thin films were then also characterized by UV-Vis absorption spectroscopy as shown in Fig. 2. The corresponding spectroscopic data are summarized in Table 3. In general, the absorption maxima of these polymers bearing 3-methoxy or 3-methylthio[3,4- $b]$ thiophene-2-carboxylate in solution and in films showed blue-shifts compared with the related polymers, which did not have substitution at the C3-position. ${ }^{12}$ This means that the steric hindrance of these substitutions at the C3-position likely disrupted the conjugation of the polymer chain. Thiomethylation of the polymers lead to larger blue-shifts in the absorption spectra compared to methoxylation of the polymers. ${ }^{2,13}$ On the other hand, Fig. $2 \mathrm{a}$ and $\mathrm{b}$ reveal that the absorption peaks of the polymers in thin films are slightly red-shifted compared to their absorptions in $\mathrm{CHCl}_{3}$. This likely indicates that the polymers form slightly stronger intermolecular interactions and molecular aggregation in the solid film than in the dilute solution state. Finally, gel
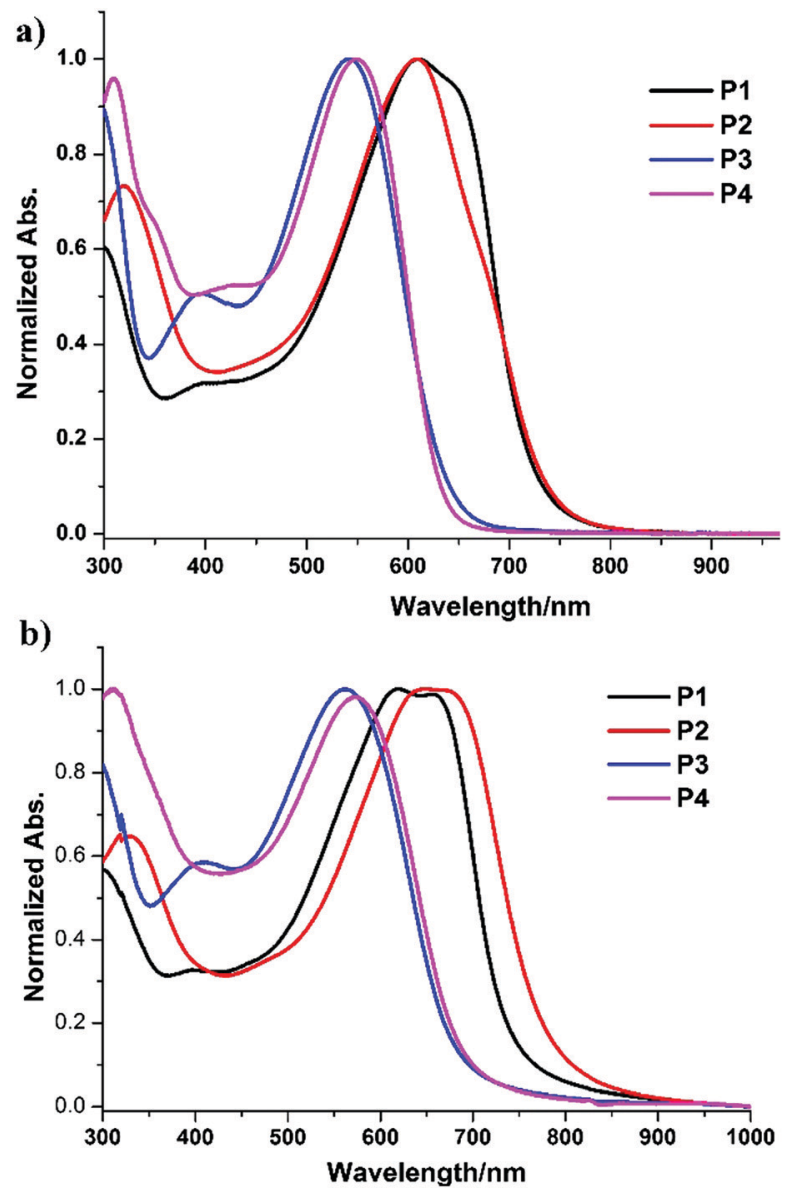

Fig. 2 Normalized UV/Vis absorption spectra of P1, P2, P3, and P4 in a chloroform solution (a) and as a solid film (b).
Table 3 Optical of properties of P1, P2, P3, and P4 in both the film state and $\mathrm{CHCl}_{3}$ solution

\begin{tabular}{|c|c|c|c|c|c|c|c|}
\hline \multirow[b]{3}{*}{$\mathrm{P}$} & \multicolumn{3}{|c|}{ UV-Vis absorption } & \multicolumn{2}{|l|}{$\mathrm{CV}^{c}$} & \multicolumn{2}{|l|}{$\mathrm{GPC}^{d}$} \\
\hline & $\lambda_{\max }^{a}$ & $\lambda_{\max }^{a}$ & $E_{\mathrm{g}}^{\mathrm{opt} b}$ & & & & \\
\hline & Sol & Film & Film & LUMO & HOMO & $M_{\mathrm{n}}(\mathrm{kD})$ & PDI \\
\hline P1 & 608 & 637 & 1.65 & 3.43 & 5.08 & 14.4 & 2.1 \\
\hline P2 & 619 & 660 & 1.56 & 3.47 & 5.03 & 10.8 & 1.9 \\
\hline P3 & 541 & 561 & 1.82 & 3.46 & 5.28 & 21.2 & 1.9 \\
\hline P4 & 549 & 572 & 1.80 & 3.46 & 5.26 & 12.3 & 2.1 \\
\hline
\end{tabular}

${ }^{a}$ Determined from UV-Vis absorption spectroscopy in $\mathrm{CHCl}_{3}$ and as a thin film. ${ }^{b}$ Estimated from the onset wavelength of the optical absorption: $E_{\mathrm{g}}^{\mathrm{opt}}=1240 / \lambda_{\text {edge }}{ }^{c} V s$. $\mathrm{Ag} / \mathrm{Ag}^{+}$in acetonitrile solution with $0.1 \mathrm{M} n-\mathrm{Bu}_{4} \mathrm{NPF}_{6}$ as a supporting electrolyte. ${ }^{d}$ Molecular weights measured using gel permeation chromatography (against polystyrene standards) in chlorobenzene at $80{ }^{\circ} \mathrm{C}$.

permeation chromatography (GPC) was also measured to obtain the molecular weights. It showed average $M_{\mathrm{n}}$ of $14.4,10.8,21.2$, and $12.3 \mathrm{kDa}$ for P1, P2, P3, and P4, respectively. The polydispersity index (PDI) of these polymers was determined to be about 1.8-2.1. Notably, all the polymers are soluble in chloroform $\left(\mathrm{CHCl}_{3}\right)$, chlorobenzene (CB), and 1,2-dichlorobenzene (DCB).

From the absorption onset in films, the optical bandgaps are evaluated to be 1.65, 1.56, 1.82, and $1.80 \mathrm{eV}$ for P1, P2, P3, and $\mathbf{P 4}$, respectively. In general, the introduction of a thiomethyl group led to significant broader optical bandgaps. To further study the energy level and band gap of these polymers, electrochemical cyclic voltammetry (CV) has also been employed to measure their redox properties (Fig. S2 and S3 in the ESI $\dagger$ ). On incorporation into the reductive onset potentials and the optical bandgaps, the LUMO/HOMO energy levels are estimated to be $-3.43 /-5.08 \mathrm{eV}$ (P1), -3.47/-5.03 eV (P2), -3.46/-5.28 eV (P3), and $-3.46 /-5.26 \mathrm{eV}(\mathbf{P 4})$.

\section{Conclusions}

In conclusion, we have developed the first Pd-catalytic method for the preparation of 3-hydroxythieno[3,4- $b]$ thiophene-2-carboxylate, which has never been prepared before our study. Furthermore, we demonstrated that 3-hydroxythieno[3,4-b]thiophene-2-carboxylate can be employed as a versatile chemical building block for modular assembly of structurally diverse 3 -substituted thieno[3,4- $b]$ thiophene derivatives via hydroxy-based transformations. Additionally, the optical and electrochemical properties of these 3-substituted thieno[3,4- $b]$ thiophene derivatives were also investigated. The results revealed that the photoluminescence (PL) properties of thieno[3,4-b]thiophene-2-carboxylate can be efficiently modulated by introducing different functional groups at the C3-position. Finally, several conjugated polymers bearing 3-methoxy and 3-methylthio TbT units were also synthesized and characterized. The results indicated that we can efficiently tune the energy levels, the optical bandgaps and absorption spectra by introducing 3 -substituted thieno[3,4- $b]$ thiophene derivatives into polymers. The device fabrication, measurements and optimization are currently underway in our lab. 


\section{Conflicts of interest}

There are no conflicts to declare.

\section{Acknowledgements}

We are grateful for the financial support from the National Natural Science Foundation of China (21871146 and 21602115), 1000-Talent Youth Program (020/BF180181), the Natural Science Foundation of Tianjin (18JCYBJC20400), the Fundamental Research Funds for the Central Universities and Nankai University.

\section{Notes and references}

1 (a) I. F. Perepichka and D. F. Perepichka, Handbook of Thiophene-based Materials: Applications in Organic Eletronics and Photonics, Wiley-VCH, Weinheim, 2009; (b) H. Yao, L. Ye, H. Zhang, S. Li, S. Zhang and J. Hou, Chem. Rev., 2016, 116, 7397; (c) A. Mishra, C.-Q. Ma and P. Bäuerle, Chem. Rev., 2009, 109, 1141; (d) M. E. Cinar and T. Ozturk, Chem. Rev., 2015, 115, 3036.

2 C. Zhang and X. Zhu, Acc. Chem. Res., 2017, 50, 1342.

3 For some examples on the PTB series family polymers as the donors in OSCs, see: (a) Y. Liang, Y. Wu, D. Feng, S.-T. Tsai, H.-J. Son, G. Li and L. Yu, J. Am. Chem. Soc., 2009, 131, 56; (b) Y. Liang, D. Feng, Y. Wu, S.-T. Tsai, G. Li, C. Ray and L. Yu, J. Am. Chem. Soc., 2009, 131, 7792; (c) J. Hou, H.-Y. Chen, S. Zhang, R. I. Chen, Y. Yang, Y. Wu and G. Li, J. Am. Chem. Soc., 2009, 131, 15586; (d) Y. Liang, Z. Xu, J. Xia, S.-T. Tsai, Y. Wu, G. Li, C. Ray and L. Yu, Adv. Mater., 2010, 22, 135; (e) Y. Huang, X. Guo, F. Liu, L. Huo, Y. Chen, T. P. Russell, C. C. Han, Y. Li and J. Hou, Adv. Mater., 2012, 24, 3383; $(f)$ Z. He, B. Xiao, F. Liu, H. Wu, Y. Yang, S. Xiao, C. Wang, T. P. Russell and Y. Cao, Nat. Photonics, 2015, 9, 174.

4 For some examples on the organic small molecules bearing TbT units as the donors in OSCs, see: (a) F. Liu, G. L. Espejo, S. Qiu, M. M. Oliva, J. Pina, J. S. S. de Melo, J. Casado and X. Zhu, J. Am. Chem. Soc., 2015, 137, 10357; (b) S. Xu, Z. Zhou, H. Fan, L. Ren, F. Liu, X. Zhu and T. P. Russell, J. Mater. Chem. A, 2016, 4, 17354.

5 For some examples on the use of the TbT units in the development of non-fullerene acceptors in OSCs, see: (a) F. Liu, Z. Zhou, C. Zhang, T. Vergote, H.j. Fan, F. Liu and X. Zhu, J. Am. Chem. Soc., 2016, 138, 15523; (b) F. Liu, Z. Zhou, C. Zhang, J. Zhang, Q. Hu, T. Vergote, F. Liu,
T. P. Russell and X. Zhu, Adv. Mater., 2017, 29, 1606574; (c) F.-X. Chen, J.-Q. Xu, Z.-X. Liu, M. Chen, R. Xia, Y. Yang, T.-K. Lau, Y. Zhang, X. Lu, H.-L. Yip, A. K.-Y. Jen, H. Chen and C.-Z. Li, Adv. Mater., 2018, 30, 1803769.

6 J. H. Park, Y. G. Seo, D. H. Yoon, Y.-S. Lee, S.-H. Lee, M. Pyo and K. Zong, Eur. Polym. J., 2010, 46, 1790.

7 (a) H. Wynberg and D. J. Zwanenburg, Tetrahedron Lett., 1967, 761; (b) S. Y. Hong and D. S. Marynick, Macromolecules, 1992, 25, 4652; (c) L. Huo, Z. Li, X. Guo, Y. Wu, M. Zhang, L. Ye, S. Zhang and J. Hou, Polym. Chem., 2013, 4, 3047; (d) S. Qu, H. Wang, D. Mo, P. Chao, Z. Yang, L. Li, L. Tian, W. Chen and F. He, Macromolecules, 2017, 50, 4962.

8 For selected reviews on hydroxy-based transformations, see: (a) D.-G. Yu, B.-J. Li and Z.-J. Shi, Acc. Chem. Res., 2010, 43, 1486; (b) B. M. Rosen, K. W. Quasdorf, D. A. Wilson, N. Zhang, A.-M. Resmerita, N. K. Garg and V. Percec, Chem. Rev., 2011, 111, 1346; (c) B.-J. Li, D.-G. Yu, C.-L. Sun and Z.-J. Shi, Chem. - Eur. J., 2011, 17, 1728; (d) J. Yamaguchi, K. Muto and K. Itami, Eur. J. Org. Chem., 2013, 19; (e) M. Tehetena and N. K. Garg, Org. Process Res. Dev., 2013, 17, 129; $(f)$ A. Correa, J. Cornella and R. Martin, Angew. Chem., Int. Ed., 2013, 52, 1878; $(g)$ M. Tobisu and N. Chatani, Top. Organomet. Chem., 2013, 44, 35; (h) F.-S. Han, Chem. Soc. Rev., 2013, 42, 5270; ( $i$ ) H. Zeng, Z. Qiu, A. Domínguez-Huerta, Z. Hearne, Z. Chen and C.-J. Li, ACS Catal., 2017, 7, 510.

9 Reviews on cross-coupling: (a) N. Miyaura, S. L. Buchwald, K. Fugami and T. Hiyama, Cross-Coupling Reactions: A Practical Guide, ed. N. Miyaura, Springer: Berlin, Germany, 2002; (b) F. Diederich and A. de Meijere, Metal-Catalyzed Cross-Coupling Reactions, ed. F. Diederich and A. de Meijere, Wiley-VCH, Weinheim, Germany, 2004; (c) A. Suzuki and Y. Yamamoto, Chem. Lett., 2011, 40, 894.

10 (a) Y.-C. Chen, H.-H. Chou, M. C. Tsai, S.-Y. Chen, J. T. Lin, C.-F. Yao and K. Chen, Chem. - Eur. J., 2012, 18, 5430; (b) J. Duan, Y. Duan, Y. Zhao, B. He and Q. Tang, Chem. Commun., 2017, 53, 10046.

11 (a) Y. Liang and L. Yu, Acc. Chem. Res., 2010, 43, 1227; (b) H. Yao, L. Ye, H. Zhang, S. Li, S. Zhang and J. Hou, Chem. Rev., 2016, 116, 7397.

12 L. Huo, S. Zhang, X. Guo, F. Xu, Y. Li and J. Hou, Angew. Chem., Int. Ed., 2011, 50, 9697.

13 (a) D. Lee, E. Hubijar, G. Jones, D. Kalaw and J. P. Ferraris, Chem. Mater., 2012, 24, 2534; (b) J. A. Schneider, A. Dadvand, W. Wen and D. F. Perepichka, Macromolecules, 2013, 46, 9231. 